\title{
A rare case of tuberculous pyopneumothorax
}

\section{Petru Emil Muntean ${ }^{\circledR}$, Ioana Pascu}

Pitesti County Hospital, Pitesti, Romania

A divorced 37-year-old male from an urban enviroment with a history of known childhood tuberculosis (TB) complained of having the following symptoms over the past 3 months: anorexia, fatigue, exertional dyspnea, left-sided chest pain, excess sweating during the night, a persistent mild elevation of body temperature above normal, productive cough, and a reduction of total body mass by 9 kilograms. Upon admission, physical examination revealed tachycardia and an oxygen saturation of $81 \%$ while breathing room air. Lung auscultation was abnormal. Routine tests conducted revealed the following: an oropharyngeal swab test for SARS-CoV-2 by RT-PCR assay was negative; hemoglobin $-10.6 \mathrm{~g} / \mathrm{dL}$; hematocrit $-38.9 \%$; red blood cell count $-5.9810^{12} / \mathrm{L}$; white blood cell count - $18.7810^{9} / \mathrm{L}$; neutrophils - $5.1210^{9} / \mathrm{L}$; lymphocytes - 42\%; HIV test - negative. Chest X-ray revealed an air fluid level in the left hemithorax and a minimum deviation of the mediastinum to the right side (Figure 1). Chest CT showed a left hydropneumothorax. Ultrasound-guided thoracentesis was implemented and 2 liters of pleural effusion were removed (Figure 2). Both sputum and pleural fluid samples were analyzed, and the results confirmed an exudative lymphocytic effusion with an ADA level of 58 U/L[1]. Ziehl-Neelsen staining revealed acid-fast bacilli, and culture of pleural pus on Lowenstein-Jensen medium displayed colonies that were non-pigmented, dry, rough, raised, and irregular with a wrinkled surface. The patient received a broad-spectrum antibiotic, an oral corticosteroid, and anti-TB treatment (regimen I) according to Romanian Guidelines. On 6-month follow-up evaluation, the patient had a good clinical response and no sequelae of pleural thickening. The combination of pneumothorax and pulmonary emphysema is a rather unusual occurrence [2], but certain underlying circumstances like TB may boost the risk of pleural diseases $[3,4]$. If treatment fails, preoperative evaluation can be unavoidable [5].
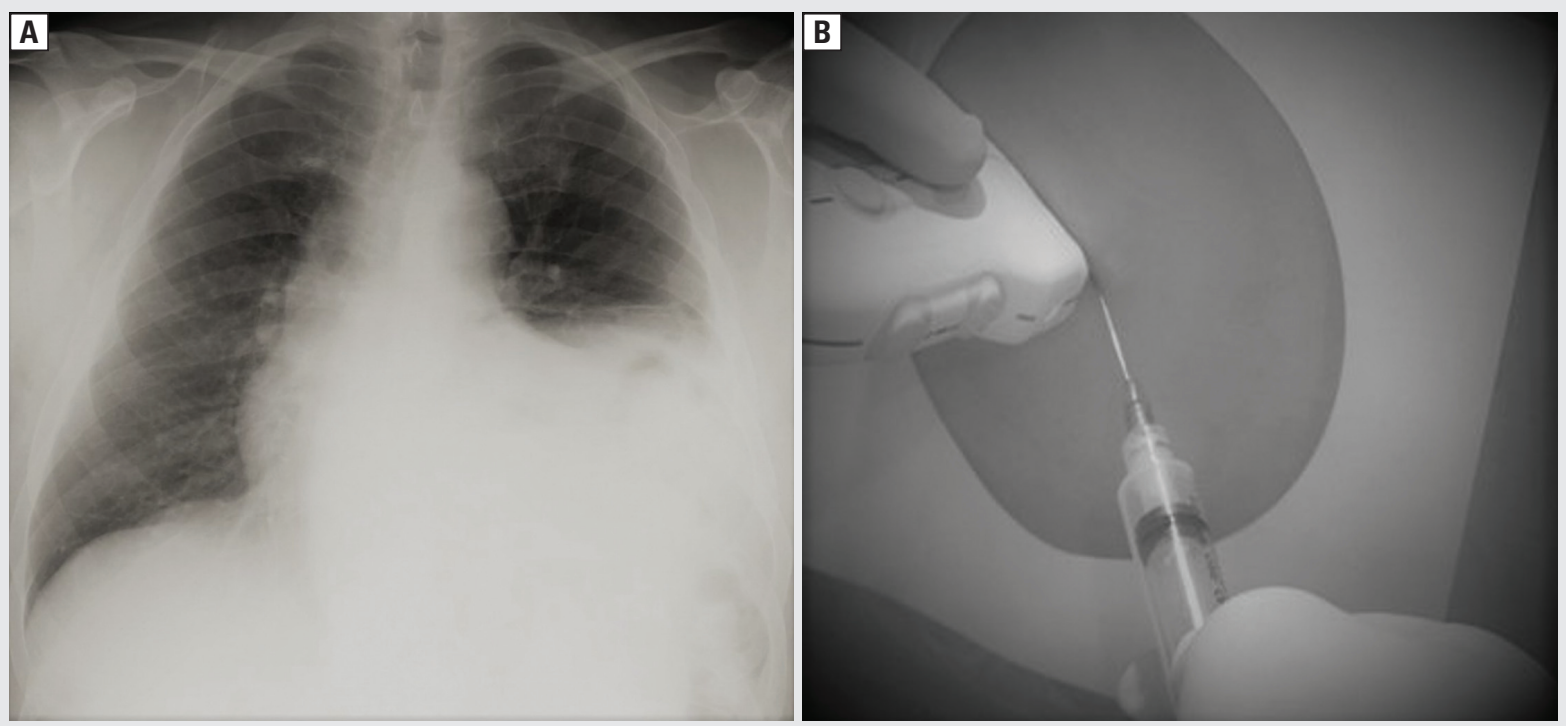

Figure 1. A. Chest X-ray; B. Ultrasound-guided thoracentesis

Address for correspondence: Petru Emil Muntean, Pitesti County Hospital, Aleea Spitalului Nr. 36, 110084 Pitesti, Romania, e-mail: muntean.petruemil@yahoo.com Conflict of interest: None declared.

DOI: 10.5603/ARM.a2021.0100 | Received: 11.04.2021 | Copyright (C 2021 PTChP | ISSN 2451-4934 | e-ISSN 2543-6031

This article is available in open access under Creative Common Attribution-Non-Commercial-No Derivatives 4.0 International (CC BY-NC-ND 4.0) license, allowing to download articles and share them with others as long as they credit the authors and the publisher, but without permission to change them in any way or use them commercially. 


\section{References:}

1. Porcel JM, Vives M. Etiology and pleural fluid characteristics of large and massive effusions. Chest. 2003; 124(3): 978-983, doi: 10.1378/chest.124.3.978, indexed in Pubmed: 12970026.

2. Light RW. Pleural Effusion. https://www.merckmanuals.com/professional/pulmonary-disorders/mediastinal-and-pleural-disorders/ pleural-effusion (10.04.2021).

3. Shaw JA, Irusen EM, Diacon AH, et al. Pleural tuberculosis: A concise clinical review. Clin Respir J. 2018; 12(5): 1779-1786, doi: 10.1111/crj.12900, indexed in Pubmed: 29660258.

4. Muntean PE. A 50-year-old male with fever, cough, dyspnoea, chest pain, weight loss and night sweats. Breathe (Sheff). 2018; 14(1): 43-48, doi: 10.1183/20734735.013317, indexed in Pubmed: 29515667.

5. Duzhyi ID. Treatment of acute pyo-pneumothorax during the tuberculosis epidemic. Klin Khir. 2003; 9: 34-37, indexed in Pubmed: 14663909. 